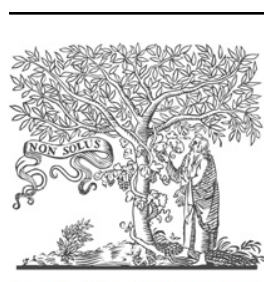

\title{
Probabilistic indoor transmission modeling for influenza (sub)type viruses
}

\author{
Szu-Chieh Chen ${ }^{\mathrm{a}, \mathrm{b}}$, Chung-Min Liao ${ }^{\mathrm{c}, *}$
}

\author{
a Department of Public Health, Chung Shan Medical University, Taichung, Taiwan 40242, ROC \\ b Department of Family and Community Medicine, Chung Shan Medical University Hospital, Taichung, Taiwan 40242, ROC \\ c Department of Bioenvironmental Systems Engineering, National Taiwan University, Taipei, Taiwan 10617, ROC
}

Accepted 29 September 2009

\section{KEYWORDS Influenza; Indoor transmission; Infection; Modeling; Vaccine}

\begin{abstract}
Summary Objectives: To use a probability based transmission modeling approach to examine the influenza risk of infection virus in indoor environments. This was based on 10 years of data gathered from influenza-like illness sentinel physician and laboratory surveillance, and experimental viral shedding data in Taiwan.

Methods: We integrated sentinel physician-reported cases and positive rates of influenza $A$ (H1N1), A (H3N2), influenza B, and respiratory syncytial virus in Taiwan using the Wells-Riley mathematical model. This model incorporates environmental factors such as room ventilation and breathing rates. We also linked vaccine match rate with related transmission estimations to predict the controllable potential using a control model characterized by basic reproduction number $\left(R_{0}\right)$ and proportion of asymptomatic infections $(\theta)$.

Results: A quantitative framework was developed to better understand the infection risk and $R_{0}$ estimates of A ( $\left.\mathrm{H} 1 \mathrm{~N} 1\right), \mathrm{A}(\mathrm{H} 3 \mathrm{~N} 2)$, and $\mathrm{B}$ viruses. The viral concentration in human fluid was linked successfully with quantum generation rates to estimate virus-specific infection risks. Our results revealed that $A(H 3 N 2)$ virus had a higher transmissibility and uncontrollable potential than the $A(\mathrm{H} 1 \mathrm{~N} 1)$ and $B$ viruses.

Conclusions: Probabilistic transmission model can incorporate virus-specific data on experimental viral shedding, long-term sentinel physician and laboratory surveillance to predict virus-specific infection risks in Taiwan.

(c) 2009 The British Infection Society. Published by Elsevier Ltd. All rights reserved.
\end{abstract}

\section{Introduction}

Influenza is one of the most important infectious diseases affecting humans. The continuous threat of pandemic human influenza pandemics suggests an urgent need to conduct long-term year-round viral surveillance of individual (sub)types in order to improve our understanding of the human influenza. ${ }^{1}$ In the past, reliable estimates based on probabilistic transmission modeling for influenza virus

* Corresponding author. Tel.: +886 2 23634512; fax: +886 223626433.

E-mail address: cmliao@ntu.edu.tw (C.-M. Liao). 
(sub)types have been rare, especially those based on human influenza experimental data. ${ }^{2,3}$

Carrat et al. ${ }^{3}$ indicated that different influenza (sub)type viruses exhibit only slight differences in viral shedding, although A ( $\mathrm{H} 3 \mathrm{~N} 2)$ infections gave consistently higher viral titers compared with $\mathrm{A}(\mathrm{H} 1 \mathrm{~N} 1)$ infections. The intrinsic differences between influenza (sub)types may determine their potential infection risk in healthy individuals. By drawing on evidence derived from experimental volunteers to investigate the natural history and dynamics of viral shedding of virus (sub)types, the accuracy of the predicted outcomes of control measure programs can be ascertained.

Although influenza vaccination is still considered a commonly used intervention for containing influenza transmission worldwide, human influenza A (H1N1), A (H3N2), and influenza $B$ viruses continue to be predominant circulating strains globally. ${ }^{4-6}$ Hsieh et al. ${ }^{7}$ reported that the match rate for influenza vaccines, based on World Health Organization (WHO) figures, were $82 \%$ for A (H1N1), $53 \%$ for $A(H 3 N 2)$, and $47 \%$ for influenza $B$ virus for the period from 1997 to 2004 in Taiwan. This match rate was markedly lower than the $77 \%$ match seen in circulating strain vaccines worldwide during this time.

Currently, no simple control modeling has been used to take into account for the different influenza virus (sub)types in the $R_{0}-\theta$ control model. The basic reproduction number $R_{0}$ essentially determines the rate of spread of an epidemic and given an indication of the policy intensities required to control the epidemic. ${ }^{8,9} \theta$ represents the proportion of asymptomatic infections which arises prior to the onset of symptoms for each influenza (sub)type viruses. Fraser et al. ${ }^{10}$ have adopted these two key variables of transmission to analyze the general properties of directly transmitted agents and determine the success rate of certain public health measures for containing early-stage outbreaks. By integrating the match rate and related transmission estimations, a more useful illustration of the controllable potential can be derived based on the concept of controllability.

The monitoring of influenza activity has been undertaken by the Centers for Diseases Control, Taiwan (Taiwan CDC) since 1999. ${ }^{11,12}$ Influenza-like illness (ILI) surveillance was carried out by sentinel primary care physicians and was based on integrated clinical and virological surveillance components. ${ }^{11-13}$ There are 13 contracted collaborating laboratories distributed geographically in northern, central, southern, and eastern Taiwan. Based on the results of yearly ILI surveillance components, respiratory syncytial virus (RSV) appears to be the most frequent cause of respiratory tract infections in children. ${ }^{14,15}$

Recently, disease transmission via exhaled infectious droplets in the indoor environment has received substantial attentions. ${ }^{16,17}$ Early research has held that the upper respiratory tract (nose, mouth and throat) is the primary location of droplet formation. ${ }^{18,19}$ As such, the particle size distributions of expired droplets play a key role in the evaluation of infection risk. Duguid ${ }^{18}$ indicated that the lognormal distribution could best describe the respiratory droplet with a geometric mean (GM) of $14 \mu \mathrm{m}$ and a geometric standard deviation (GSD) of 2.6 for cough, and a GM of $8.1 \mu \mathrm{m}$ with a GSD of 2.3 for sneeze. Papineni and Rosenthal ${ }^{20}$ measured expired bioaerosol droplets to be less than $2 \mu \mathrm{m}$ in size with no droplets larger than $8 \mu \mathrm{m}$ in the nose and mouth when breathing, coughing, and talking.

Our previous studies ${ }^{21,22}$ have focused on the transmission and control measure modeling by integrating the Wells-Riley mathematical model and a deterministic epidemiological susceptible-exposed-infected-recovery (SEIR) model. These models were used to estimate age group-specific infection risks in the indoor environments throughout summer and winter seasons. In this study, we integrated the sentinel physician-reported cases and positive rates of influenza $A$ (H1N1), A (H3N2), B, and RSV in Taiwan with the Wells-Riley mathematical model. This model allows for the incorporation of environmental factors such as room ventilation and breathing rates. The objective of this study was to employ the probabilistic transmission modeling approach to examine the virus-specific infection risk in the indoor environments. Our model incorporates data based on 10 years of ILI sentinel physician and laboratory surveillance, and experimental viral shedding data in Taiwan.

\section{Materials and methods}

\section{ILI sentinel physician and laboratory surveillance}

Weekly-based ILI sentinel physician surveillance data in Taiwan were obtained from Taiwan CDC for the period from

Table 1 Epidemiological periods of influenza A (H1N1), A (H3N2), and influenza B virus.

\begin{tabular}{|c|c|c|c|c|c|}
\hline $\begin{array}{l}\text { Infectious } \\
\text { disease }\end{array}$ & $\begin{array}{l}\text { Incubation } \\
\text { period (days) }\end{array}$ & $\begin{array}{l}\text { Latent } \\
\text { period (days) }\end{array}$ & $\begin{array}{l}\text { Infectious } \\
\text { period (days) }\end{array}$ & $\begin{array}{l}\text { Mean duration } \\
\text { of illness (days) }\end{array}$ & $\begin{array}{l}\text { Mean duration } \\
\text { of viral } \\
\text { shedding (days) }\end{array}$ \\
\hline Influenza & $\begin{array}{l}1-4^{a} \\
1-3^{b} \\
1-3^{d}\end{array}$ & $\begin{array}{l}1-3^{a} \\
1.9^{c} \\
1-3^{d}\end{array}$ & $\begin{array}{l}4-8^{a} \\
4.1^{c} \\
2-3^{d}\end{array}$ & & \\
\hline A (H1N1) & & & & $4.4-5^{e}$ & $3.70(1.73,5.66)^{\mathrm{e}}$ \\
\hline A (H3N2) & & & & $3.7^{\mathrm{e}}$ & $4.50(3.71,5.28)^{\mathrm{e}}$ \\
\hline B & & & & $4.1^{\mathrm{e}}$ & $5.14(4.48,5.80)^{\mathrm{e}}$ \\
\hline $\begin{array}{ll}\text { a } & \text { Adopted } \\
\text { b } & \text { Adopted } \\
\text { c } & \text { Adopted } \\
\text { d } & \text { Adopted } \\
& \text { ented }\end{array}$ & $\begin{array}{l}\text { nderson and Ma } \\
\text { homas and Web } \\
\text { Aills et al. }{ }^{34} \\
\text { inderson. }{ }^{35}\end{array}$ & & & & \\
\hline
\end{tabular}



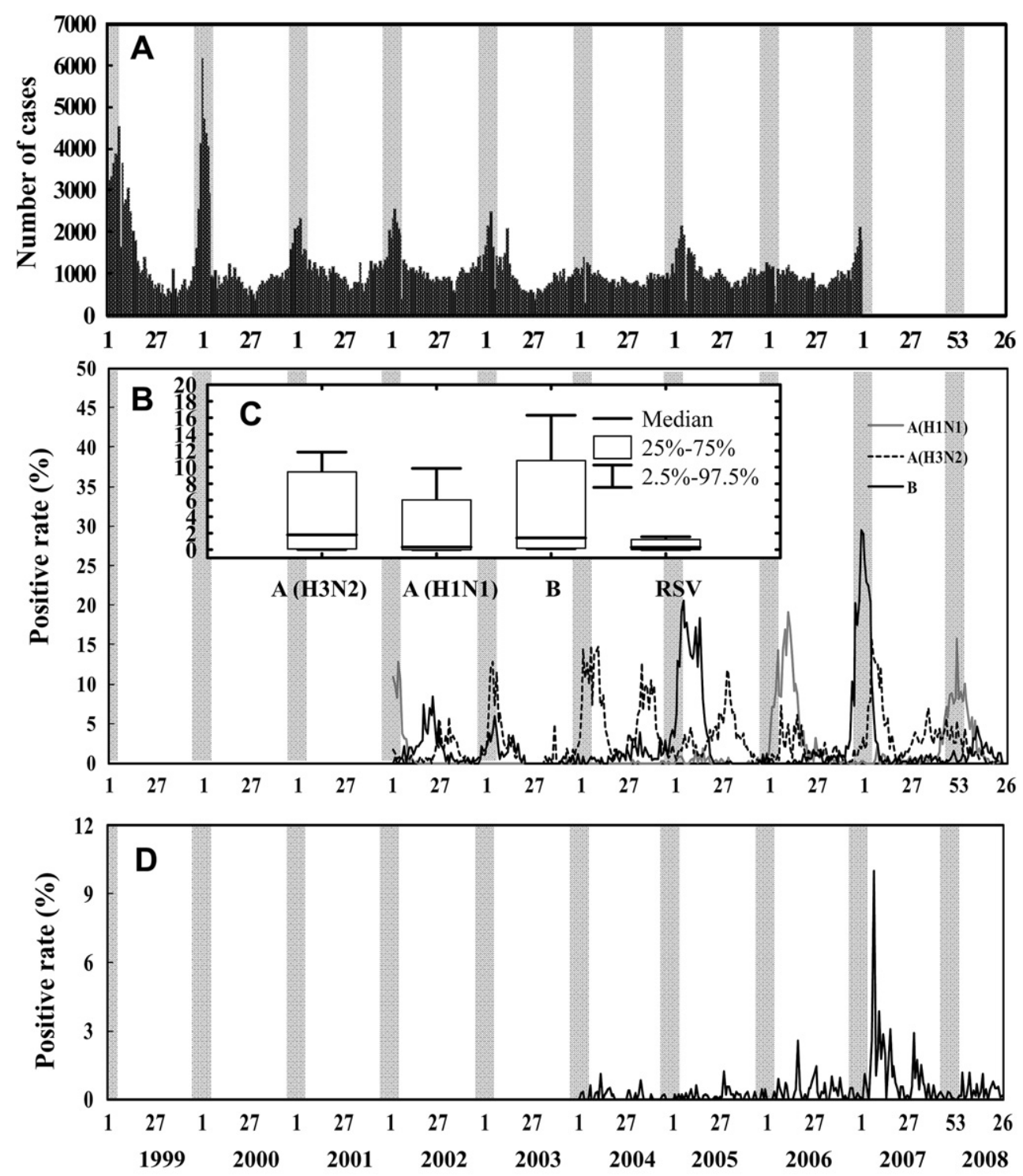

Time (year/week)

Figure 1 (A) Weekly-based influenza-like illness (ILI) sentinels physician surveillance in Taiwan area for the year 1999-2006. (B) Weekly-based positive rate of influenza $A(H 1 N 1), A(H 3 N 2)$, and influenza B viruses from 2002 to 2008 . (C) The box and whisker plot of positive rate of influenza $A(\mathrm{H} 3 \mathrm{~N} 2), \mathrm{A}(\mathrm{H} 1 \mathrm{N1} 1), \mathrm{B}$, and respiratory syncytial virus (RSV). (D) Weekly-based positive rate of RSV from 2004 to 2008.

1999 to 2006. This data represent ILI cases reported in patients under outpatient and hospital care in all medical centers and teaching hospitals in Taiwan. The case definition of ILI included patients with fever (ear temperature over $38^{\circ} \mathrm{C}$ ), and respiratory symptoms and signs such as myalgia, headache, and fatigue. ${ }^{11}$

Weekly data on influenza (sub)type isolates in various regions around Taiwan were obtained from Taiwan CDC for the period from 2002 to 2008. The positive rates of influenza $A(\mathrm{H} 1 \mathrm{~N} 1), A(\mathrm{H} 3 \mathrm{~N} 2)$, and influenza $B$ viruses were determined by the percentage of respiratory tract infections that were positive for influenza each week. Data relating to the positive rates of RSV were also obtained from Taiwan CDC for the period from 2004 to 2008.
The biological characteristics and pathogenesis of each influenza (sub)types is summarized in Table 1. Natural history provides the baseline for estimating the proportion of asymptomatic infections $(\theta)$ for each influenza (sub)type. We assumed the values for incubation period, latent period, and mean duration of viral shedding to be a normal distribution. The estimation of $\theta$ was thus calculated by dividing the probability distribution of the asymptomatic infection period with the probability distribution of the mean duration of viral shedding. The Monte Carlo simulation was performed to quantify the uncertainty of $\theta$ by using Crystal Ball software (Version 2000.2, Decisioneering, Inc., Denver, CO, USA). Table Curve 2D (Version 5.01, AISN Software Inc., Mapleton, OR, USA) was used to perform model fitting techniques. 


\section{Quantum generation rate for different influenza (sub)types}

In this study, the "infectious dose" of virus was quantified by the concept of "quantum." We adapted the concept based on Nicas et al. ${ }^{16}$ in order to estimate quantum for influenza virus (sub)types. This was achieved by quantifying the risk of secondary airborne infection based on the characteristics of emission of respiratory pathogens. We therefore considered two parameters that might affect quantum estimation, particle size diameter and days post infection. We used a particle size diameter $\leq 10 \mu \mathrm{m}$ to estimate airborne infection risk and defined quantum with the following equation, ${ }^{18,19}$

$q(t, x)=E \times C_{t} \times N_{x} \times \bar{\nu}_{x}$,

where $q(t, x)$ is the quantum generation rate varying with the day post infection $(t)$ and the particle size diameter $x \leq 10 \mu \mathrm{m}\left(\operatorname{TCID50~}^{-1}\right), E$ is the expulsion event rate by sneeze (event $\mathrm{hr}^{-1}$ ), $C_{t}$ is the influenza virus (sub)type shedding in respiratory fluid (TCID50 ml ${ }^{-1}$ ), $N_{x}$ is the particle number concentration in each particle size diameter $x\left(\mathrm{ml}^{-1}\right)$, and $\bar{v}_{x}$ is the particle volume per expulsion event $(\mathrm{ml})$.

The best-fitting model for viral shedding of influenza $A$ (H1N1), A (H3N2), and B viruses were obtained from experimental data ${ }^{3}$ as provided by 116, 41 , and 8 participants who shed influenza viruses, respectively. The sum of the total particle volumes at specific particle size diameter $x$ can be expressed as $N_{x} \times \bar{v}_{x}$. We adopted the available experimental data from Duguid ${ }^{18}$ to describe the relationship between the particle size diameter and droplet number concentration of sneeze. The relationship between the particle volume and the number of particles emitted per sneeze was adopted from Loudon and Roberts. ${ }^{19}$

\section{Wells-Riley mathematical equation}

The Wells-Riley mathematical equation was used to estimate the indoor airborne infection risk in an enclosed
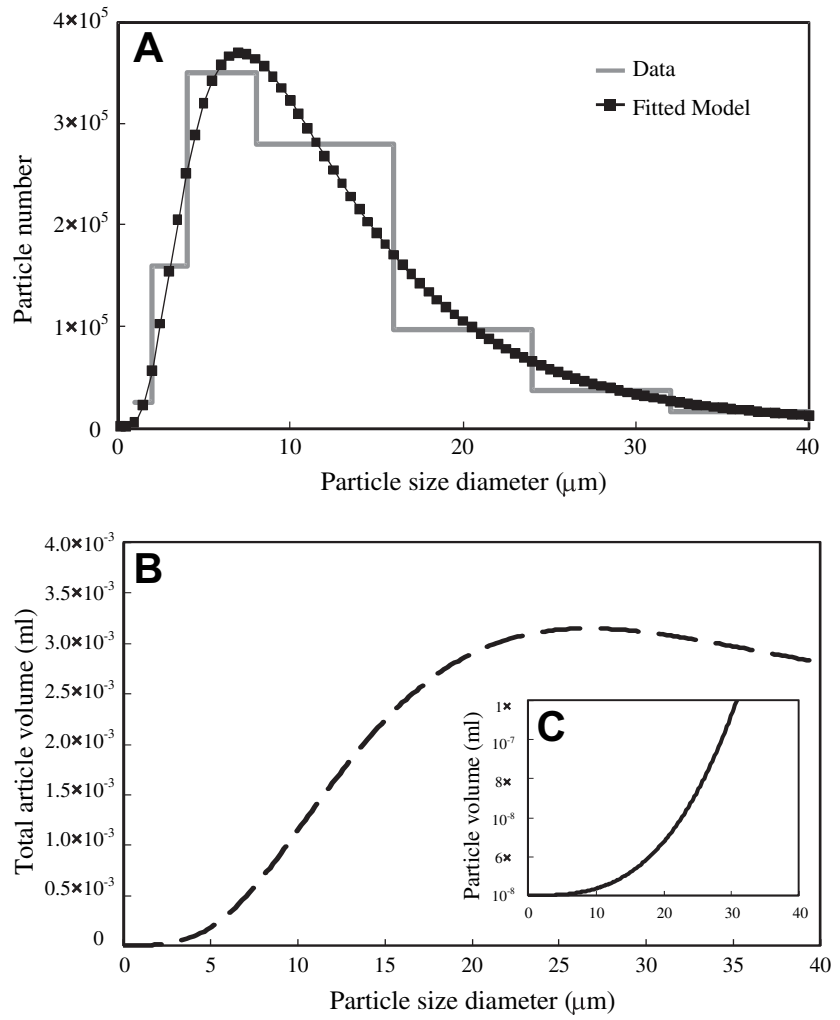

Figure 2 (A) The original experimental data for sneeze from Duguid $^{18}$ shows the relationship between particle size diameter and particle number concentration. (B) The size-dependent total particle volume for sneeze which are estimated by Fig. 2A and Fig. $2 C$, in that $(C)$ was the best fitted model to the data Duguid $^{18}$ and describing the relationship between the particle size diameters corresponding to the particle initial volume per sneeze from diameter 0 to $40 \mu \mathrm{m}$.

space. Riley et al. ${ }^{23}$ made two assumptions to quantify the indoor respiratory infections. The first assumption implies that an infectious droplet nucleus has an equal chance of

Table 2 Optimal fitted equations of particle number, time-dependent virus concentration in respiratory fluid, size-dependent total particle volume per expulsion event of cough.

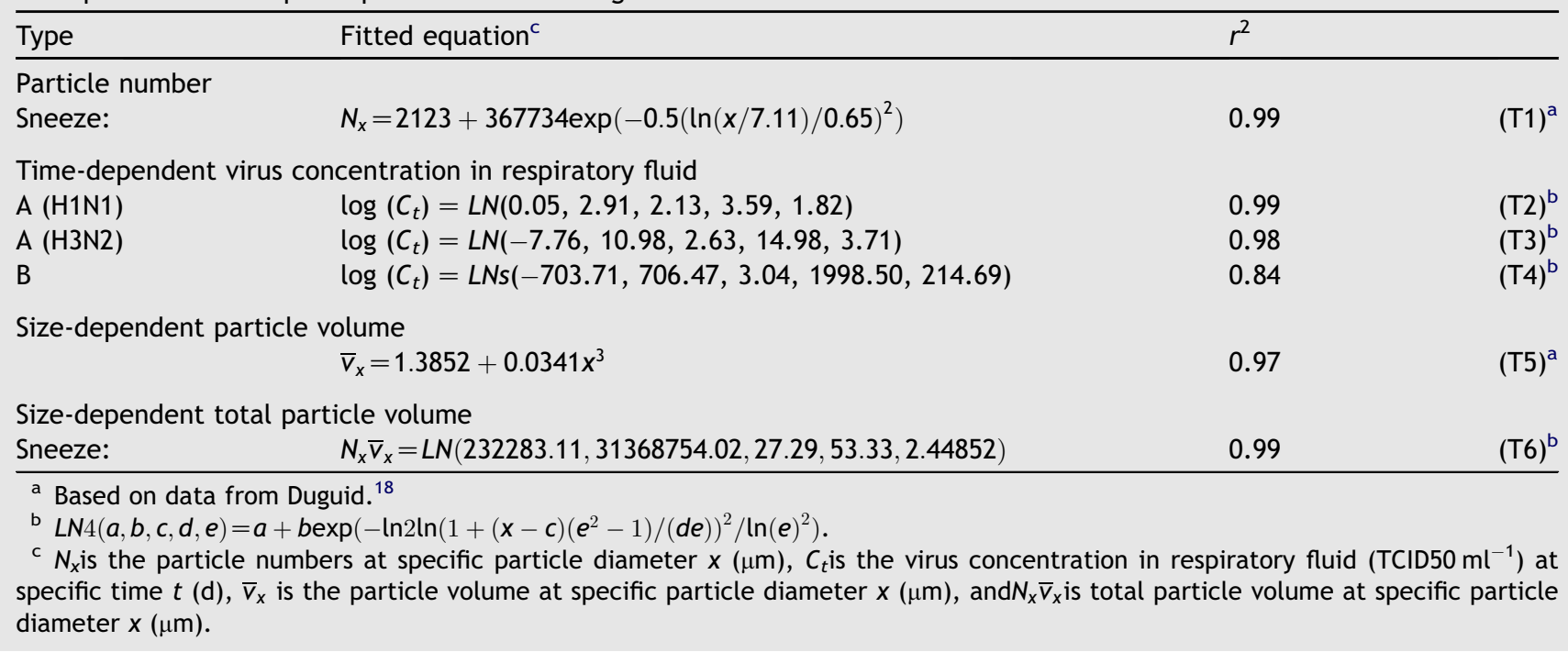




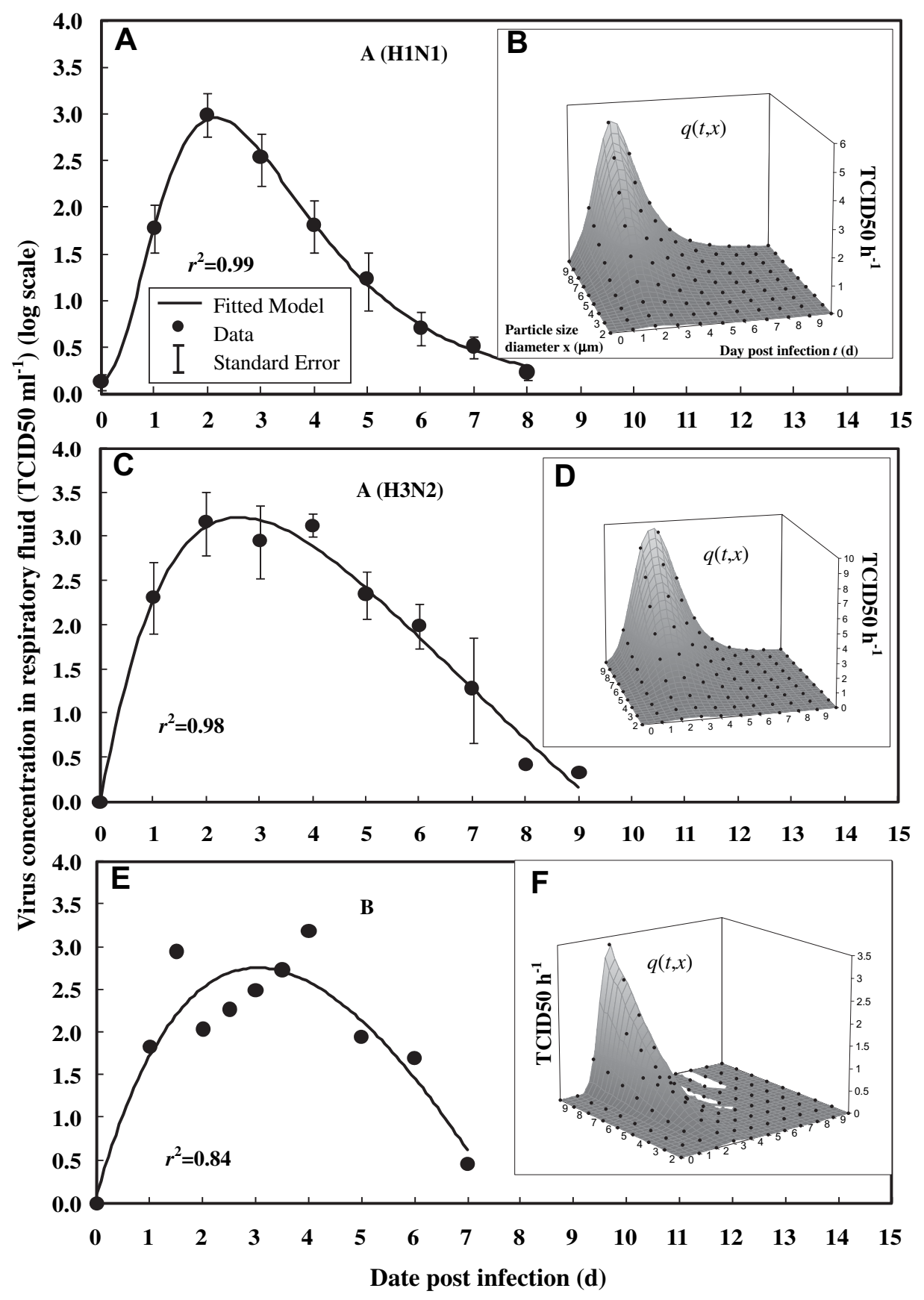

Figure $3(A, C$, and $E)$ represented the viral dynamics of influenza $A(H 1 N 1), A(H 3 N 2)$, and influenza $B$ viruses, respectively, and $(B, D$, and $F)$ illustrated the quantum generation rate $q(t, x)$ for sneeze in that $t$ expressed the day post infection (day) and $x$ expressed the particle size diameter $(\mu \mathrm{m})$.

being anywhere within a building's airspace. The second assumption implies that the quantum concentration and the outdoor air supply rate remain constant with time.

We modified the Wells-Riley mathematical equation to estimate the transmission potential of influenza (sub)type viruses in a hospital setting, ${ }^{24}$

$P=\frac{D}{S}=1-\exp \left\{-\frac{l q_{\max } p t}{Q}\left\{1-\frac{V}{Q t}\left[1-\exp \left(-\frac{Q t}{V}\right)\right]\right\}\right\}$,

where $P$ is the probability of infection for susceptible population varied with influenza (sub)type, $S$ is the number of susceptible individuals, $D$ is the number of positive cases among $S$ individuals susceptible to the infection, $I$ is the number of sources of infection, $q_{\max }$ is the maximum value of the modeling results of $q(t, x)\left(\operatorname{TCID} 50 \mathrm{~h}^{-1}\right), p$ is the pulmonary ventilation rate of susceptible individuals $\left(\mathrm{m}^{3} \mathrm{~d}^{-1}\right), t$ is the exposure time (d), $Q$ is the fresh air supply rate that removes the infectious aerosol in volume per unit of time $\left(\mathrm{m}^{3} \mathrm{~h}^{-1}\right)$, and $V$ is the volume of the ventilated space $\left(\mathrm{m}^{3}\right)$. To model the respiratory infection risk, we incorporated $I=1$ and $S=n-1$ into Eq. (2) to estimate the $R_{0}$ for quantifying the average number of successfully secondary infection cases generated by a typical primary infected case within an entirely susceptible population as, 

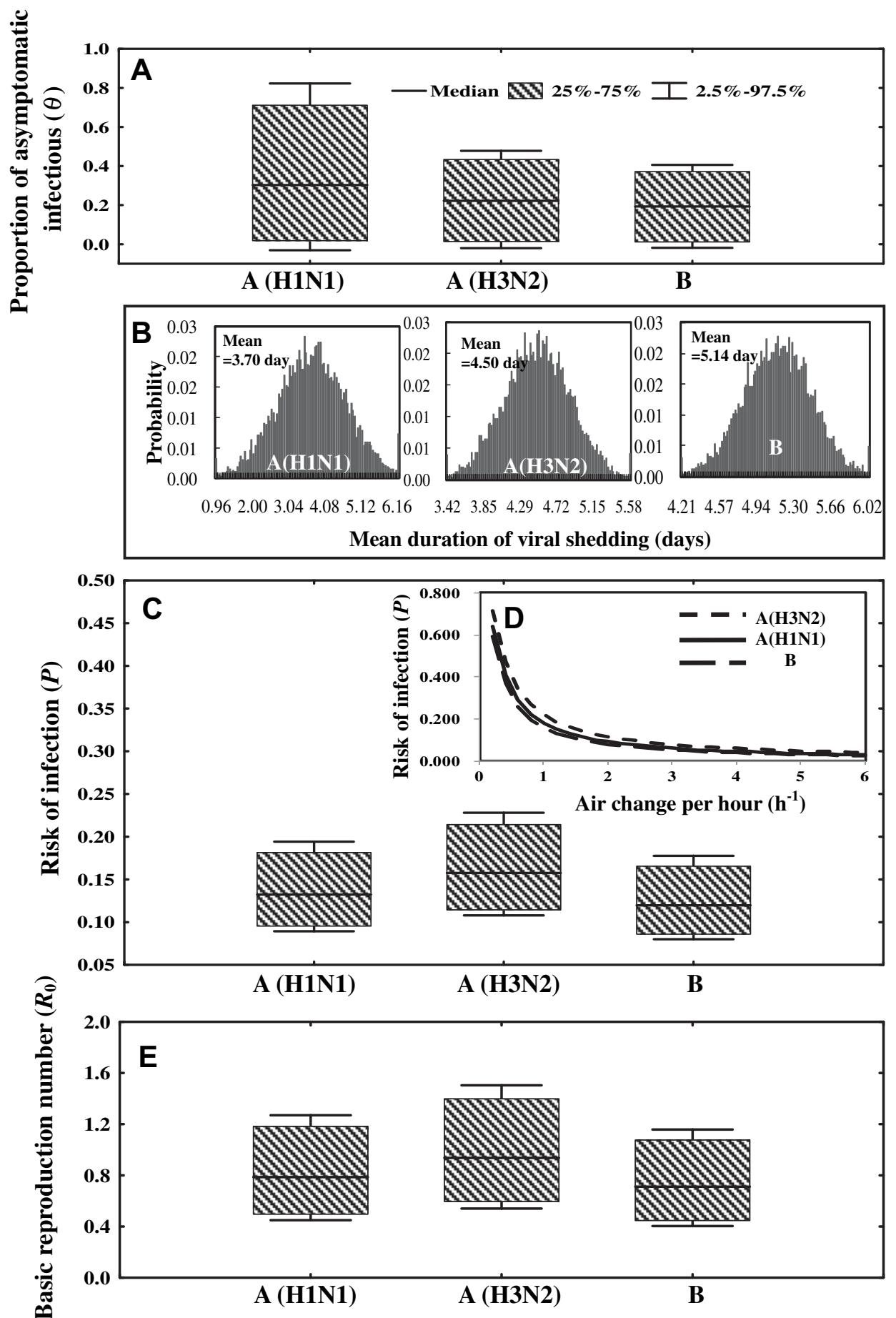

Figure 4 The box and whisker plots of $(A)$ proportion of asymptomatic infectious $(\theta)$ was presented in that (B) show the probability of mean duration of viral shedding for influenza $A(H 1 N 1), A(H 3 N 2)$, and influenza $B$ viruses, respectively. The risk of infection $(P)$, and basic reproduction number $\left(R_{0}\right)$ for influenza $A(\mathrm{H} 1 \mathrm{~N} 1), \mathrm{A}(\mathrm{H} 3 \mathrm{~N} 2)$, and influenza $\mathrm{B}$ viruses were also illustrated in that $(\mathrm{D})$ estimated the $P$ values varied with air change rate from 0 to 6 per hour.

$$
\begin{aligned}
R_{0}= & (n-1)\left\{1-\exp \left\{-\frac{q_{\max } p t}{Q}\right.\right. \\
& \left.\left.\left\{1-\frac{V}{Q t}\left[1-\exp \left(-\frac{Q t}{V}\right)\right]\right\}\right\}\right\},
\end{aligned}
$$

where $n$ represents the total number in the ventilation airspaces. The virus-specific $R_{0}$ values can then be estimated by using Eq. (3).

\section{Control measure effect of influenza vaccination}

We adopted the $R_{0}-\theta$ control curve to formulate the control measure effect. The concepts of our control model were based on those elaborated by Fraser et al. ${ }^{10}$ and used the two key parameters of $R_{0}$ and $\theta$ to predict the level of control policy required to achieve outbreak containment. 
Table 3 Input parameters used in Wells-Riley mathematical equation to estimate the basic reproduction number $\left(R_{0}\right)$.

\begin{tabular}{|c|c|c|c|}
\hline Symbol & Meaning & Value & Remark \\
\hline$n$ & People in the ventilated airspace & $\operatorname{LN}(10,1)$ & Assumed \\
\hline I & Number of infectors & 1 & Assumed \\
\hline$V$ & Volume of the shared airspace & Uniform $(250-350) \mathrm{m}^{3}$ & Assumed \\
\hline$t$ & Exposure time & Uniform $(0.25-0.33) \mathrm{d}$ & Estimated \\
\hline$p$ & Pulmonary ventilation rate of susceptible individuals & $N(11.16,0.20) \mathrm{m}^{3} \mathrm{~d}^{-1}$ & Estimated $^{\mathrm{a}}$ \\
\hline$f$ & $\begin{array}{l}\text { Fraction of indoor air as exhaled } \\
\text { breath }(f=n p / Q)\end{array}$ & 0.003875 & Estimated \\
\hline$Q$ & Fresh air supply rate (based on $Q=1 \mathrm{ACH}$ ) & $N(1.5,0.3) h^{-1}$ & Assumed \\
\hline$q_{\mathrm{A}(\mathrm{H} 1 \mathrm{~N} 1)}$ & Quantum generation rate of influenza $\mathrm{A}(\mathrm{H} 1 \mathrm{~N} 1)$ virus & $5.251 \mathrm{TCID}^{2} \mathrm{~h}^{-1}$ & Estimated $^{\mathrm{b}}$ \\
\hline$q_{\mathrm{A}(\mathrm{H} 3 \mathrm{~N} 2)}$ & Quantum generation rate of influenza A $(\mathrm{H} 3 \mathrm{~N} 2)$ virus & $9.218 \mathrm{TCID} 0 \mathrm{~h}^{-1}$ & Estimated $^{\mathrm{b}}$ \\
\hline$q_{\text {в }}$ & Quantum generation rate of influenza B virus & $3.325 \mathrm{TCID} 0 \mathrm{~h}^{-1}$ & Estimated $^{\mathrm{b}}$ \\
\hline$E$ & Number of sneeze per hr & $5 h^{-1}$ & Assumed \\
\hline
\end{tabular}

By following the parameter estimates for $R_{0}$ and $\theta$, the $R_{0}-\theta$ critical control line can be constructed from the control measure efficacy and $R_{0}$ estimate based on the Wells-Riley equation. ${ }^{24}$ Here the $R_{0}-\theta$ control curve can be written as, ${ }^{10}$

$R_{0}=[(1-\varepsilon)+\varepsilon \theta]^{-1}$,

where $\varepsilon$ is the efficacy of influenza vaccination.

Factors affecting the efficacy of influenza vaccination include vaccine coverage rate, vaccine implement methods, and predictive epidemic strains. However, we focused only on the vaccine match rates of WHO recommended influenza vaccines for strains currently circulate in Taiwan.

Based on the $R_{0}-\theta$ control curve, when a given infectious agent is situated below the $R_{0}-\theta$ curve (as denoted by $A_{1}$ ), the outbreak is always eventually controlled. Conversely, when an infectious agent lies above the curve (as denoted by $A_{2}$ ), additional control measures are required to control the spread. Therefore, The uncontrollable ratio can be estimated from the ratio of $A_{1} /\left(A_{1}+A_{2}\right)$ and can be used to assess the effectiveness of adopted control measures.

\section{Results}

\section{Data reanalysis of sentinel physician and laboratory surveillance}

Fig. 1A shows the epidemics of influenza virus in winter seasons as annual trends. Fig. $1 \mathrm{~A}$ also indicates that influenza $\mathrm{A}$ (H3N2) had observable activity during all periods, whereas influenza A (H1N1) was a dominant strain in the winters of 2005-2006 and 2007-2008. The gray bands represent the winter seasons (weeks 49-52 and weeks 1-9), which featured an average weekly reported ILI cases of 1126. Influenza B virus was a dominant strain in the winters of 2004-2005 and 2006-2007 (Fig. 1B). The uncertainties of positive rates for $A(\mathrm{H} 1 \mathrm{~N} 1), A(\mathrm{H} 3 \mathrm{~N} 2)$, and type $B$ are given in Fig. $1 \mathrm{C}$. Fig. $1 \mathrm{C}$ also indicates that median positive rates (95\% confidence interval $(\mathrm{Cl})$ ) of $1.81(0.04-11.84 \%), 0.32$ (0.01-9.86\%), $1.43(0.12-16.30 \%)$, and $1.43(0.01-1.56 \%)$ for influenza A (H3N2), A (H1N1), influenza B virus and RSV, respectively. Fig. 1D shows that the weekly-based averaged positive rate of RSV were estimated to be $0.42 \%$ during 2004-2008.

\section{Quantum generation rate for different influenza (sub)types}

Fig. 2A shows the relationship between the particle size diameter and particle number of a sneeze event, as adopted from Duguid. ${ }^{18}$ The best-fitting equation was presented in Table 2 (Eq. (T1)) with $r^{2}=0.99$. Moreover, Fig. 2B shows the correlation between particle size diameter and sizedependent total particle volume as adopted from Loudon and Roberts ${ }^{19}$ (Eq. (T6)), in that the size-dependent particle volume (Fig. 2C) was fitted by Eq. (T5) (Table 2).

In regard of the time-dependent viral concentration present in respiratory fluid $\left(C_{t}\right)$, it was revealed that the influenza A (H1N1) and A (H3N2) curves sharply increased at day 1 , reached the maximum values at day 2 , and returned to the baseline values at days $7-8$ (Fig. 3A, C). Hence, we integrated the frequency of a sneeze event per hour $(E)$ with $E=5 \mathrm{~h}^{-1}$, time-dependent virus concentration in respiratory fluid for different influenza (sub)types (Eqs. (T2)-(T4)), and size-dependent total particle volumes (Eqs. (T5) and (T6)) in order to simulate dynamics of the quantum generation rate $(q(t, x))$.

Fig. $3 B, D$, and $F$ reveals the interesting response surfaces of the influenza (sub)type-specific quantum generation rates by Eq. (1). Results indicated that the maximum quantum generation rate $\left(q_{\max }\right)$ was estimated to be 5.25 TCID50 $\mathrm{h}^{-1}$ at $\mathrm{x}=10 \mu \mathrm{m}$ and day 2 post infection with influenza A (H1N1). Influenza A (H3N2) and type B were estimated to be nearly $9.22 \mathrm{TCID} \mathrm{h} \mathrm{h}^{-1}$ and $3.33 \mathrm{TCID}_{0} \mathrm{~h}^{-1}$ at $x=10 \mu \mathrm{m}$ and day 3 post infection, respectively. These results implied that type $A$ influenza was the most virulent. The size-dependent particle number concentration of sneeze activity may explain why the $q_{\max }$ all appeared at the particle size diameter $x=10 \mu \mathrm{m}$. Fig. 2A also shows that the number of exhaled particles reaches almost to $3 \times 10^{5}-4 \times 10^{5}$ for one sneeze event. 


\section{Risk of infection and basic reproduction number}

The proportion of asymptomatic infections $(\theta)$ ranged from 0.01 to $0.82(95 \% \mathrm{Cl}), 0.01$ to 0.47 , and 0.01 to 0.40 for influenza $A(\mathrm{H} 1 \mathrm{~N} 1), A(\mathrm{H} 3 \mathrm{~N} 2)$, and $B$ viruses, respectively (Fig. 4A). The probability distributions of the mean duration of viral shedding for the three strains are shown in Fig. 4B with means of $3.7,4.5$, and 5.14 day, respectively. Result indicated that influenza A $(\mathrm{H} 1 \mathrm{~N} 1)$ virus had higher $\theta$ than the other two strains. It also showed a negative relationship with the longer mean duration of viral shedding. By using Eqs. (2) and (3), the $R_{0}$ of the Wells-Riley mathematical equation can be estimated (Table 3 ).

This study used a set of assumed values for the number of individuals in the ventilated airspace $(n)$, the volume of the shared airspace $(V)$, exposure time $(t)$, fresh air supply rate $(Q)$, and number of sneeze events per hour $(E)$ to simulate a hospital setting. Other values such as the $q_{\mathrm{A}(\mathrm{H} 1 \mathrm{~N} 1)}, q_{\mathrm{A}}$ (H3N2), and $q_{B}$ were estimated by Eq. (1). The result indicated that the box and whisker plots of median with $95 \% \mathrm{Cl}$ of infection risks $(P)$ and $R_{0}$ were estimated to be $0.132(0.09-0.19)$, 1.19 (0.76-1.86); 0.157 (0.108-0.229), 1.41 (0.92-2.19); and $0.120(0.08-0.178), 1.07(0.69-1.69)$ for $A(H 1 N 1), A$ (H3N2) and type B viruses, respectively (Fig. 4C and E). The potential transmission of infection for the three influenza viruses can be judged by $R_{0}>1$. Using the Wells-Riley mathematical equation, we also analyzed variation in the air change rate. The results demonstrated that environmental parameters contribute insignificant to the effects of virusspecific infection risk (Fig. 4D).

\section{Virus-specific $R_{0}-\theta$ relationships}

Fig. 5 shows the virus-specific $R_{0}-\theta$ critical control lines obtained by combining the two key parameters estimates of $R_{0}$ and $\theta$ (Eq. (4)). The only one control measure we considered was the year-round mass vaccination for hospital worker populations, the elderly (aged 65 and over), and other at risk populations. Vaccine efficacy was adopted from the vaccine match rates described by WHO match rates for the relevant strains circulating in Taiwan. The match rates were estimated to be $82 \%, 53 \%$, and $47 \%$ for $A(H 1 N 1)$, influenza $A(H 3 N 2)$, and type $B$ viruses, respectively (Fig. 5).

The estimates for the uncontrollable ratios were $14.9 \%$ for $A(H 1 N 1), 31.5 \%$ for $A(H 3 N 2)$, and $10 \%$ for type $B$. This indicated that the influenza $A(H 3 N 2)$ virus features a more significant uncontrollable potential. To further ascertain the effects of different match rates on controllable potentials, we modeled the $R_{0}-\theta$ critical control lines by assuming match rates of $60-90 \%, 40-70 \%$, and $30-60 \%$ for influenza A $(\mathrm{H} 1 \mathrm{~N} 1)$, influenza $A(\mathrm{H} 3 \mathrm{~N} 2)$, and influenza $B$ viruses, respectively. The results showed uncontrollable ratios ranging from 12 to $24 \%$ for $A$ (H1N1) (Fig. 5A), 12 to $57 \%$ for $A$ (H3N2) (Fig. $5 B$ ), and 1.3 to $37 \%$ for influenza $B$ (Fig. 5C).

\section{Discussion}

The nature of its interaction with the human immune system not only determines the patterns and processes of evolutionary change in influenza viruses, but also reflects how these viruses interact with each other. ${ }^{25}$ Moreover, in light of analyses of their genomic and epidemiological dynamics, the long-term monitoring of positive rate of influenza (sub)type viruses may play a specific role in reducing the year-round predominance of these (sub)types. Our results showed medians of positive rate to be $1.81 \%$ (95\% Cl 0.04-11.84), 0.32\% (0.01-9.86), and 1.43\% (0.1216.30) for $A(H 3 N 2), A(H 1 N 1)$, and type $B$ viruses, respectively, for the period from 2002 to 2008. The A (H3N2) showed higher potential positive rate than the other influenza strains. Intensive studies have been carried out to characterize the laboratory-based surveillance and molecular epidemiology of influenza (sub)type viruses in Taiwan. ${ }^{6,13,26}$ Lin et al. ${ }^{13}$ reported that $1.5 \%$ of isolates were A $(\mathrm{H} 1 \mathrm{~N} 1), 21.5 \%$ were $A(\mathrm{H} 3 \mathrm{~N} 2)$, and $77.0 \%$ were type $B$ viruses during the 2006-2007 period in Taiwan. The
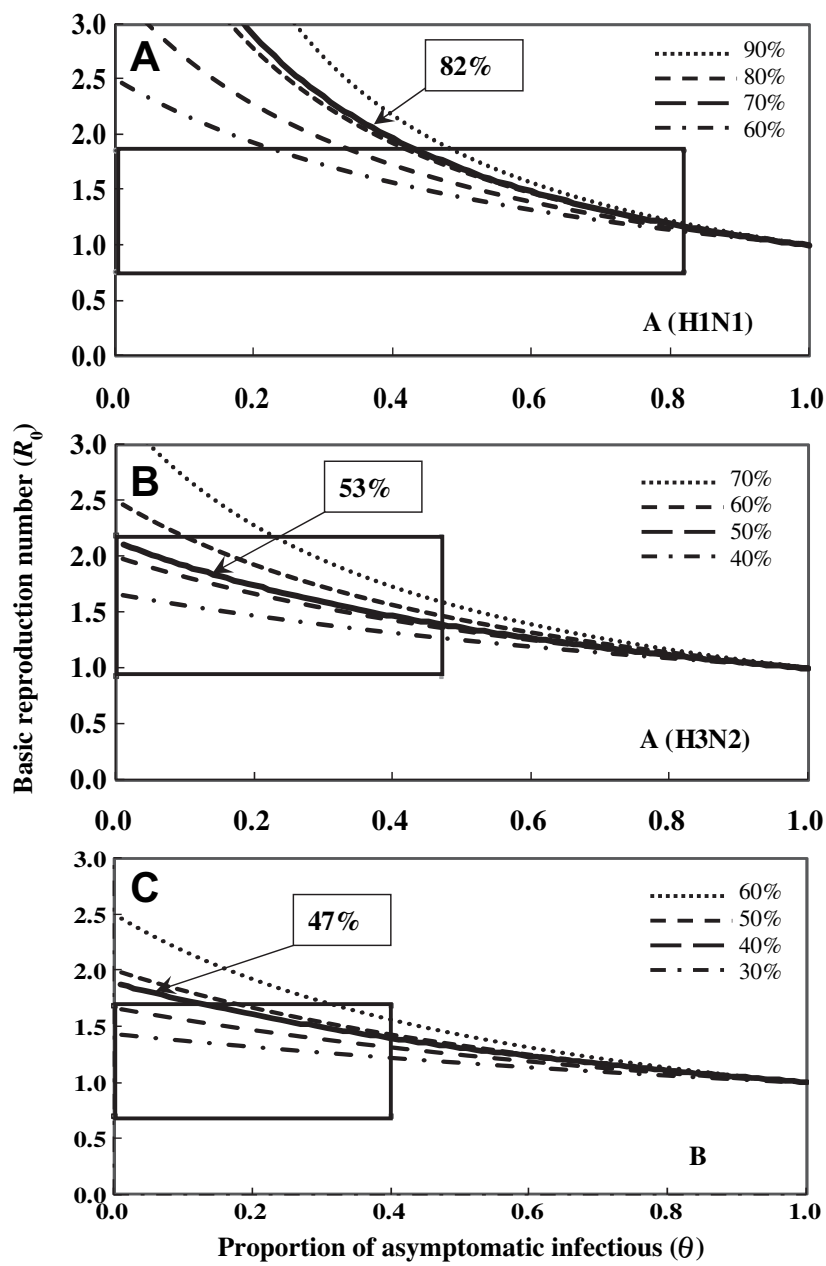

Figure. $5 \quad(A)-(C)$ represent the associated with the estimates of $95 \% \mathrm{Cl}$ of basic reproduction number $\left(R_{0}\right)$ and the $95 \% \mathrm{Cl}$ of the proportion of asymptomatic infection $(\theta)$ for influenza $A(\mathrm{H} 1 \mathrm{~N} 1), A(\mathrm{H} 3 \mathrm{~N} 2)$, and influenza $B$ viruses, respectively. We assumed that the match rates of WHO-commended vaccine compositions with circulating strains in Taiwan are (A) 60-90\%, (B) $40-70 \%$, and (C) $30-60 \%$, respectively. An area above the curve (denoted as $\mathrm{A}_{2}$ ) means additional control measures would be required to control the spread. 
Table 4 Estimation of basic reproduction number and proportion of asymptomatic infectious for influenza (sub)type viruses.

\begin{tabular}{|c|c|c|c|c|}
\hline & \multirow[t]{2}{*}{ Seasonal influenza } & \multicolumn{3}{|l|}{ Influenza (sub)type } \\
\hline & & A (H1N1) & $\mathrm{A}(\mathrm{H} 3 \mathrm{~N} 2)$ & B \\
\hline Basic reproduction number $\left(R_{0}\right)$ & $\begin{array}{l}1.5^{\mathrm{a}} \\
0.9-2.1^{\mathrm{c}}\end{array}$ & $\begin{array}{l}2.68^{b} \\
1.8-4.4^{d} \\
2-3^{c}\end{array}$ & $\begin{array}{l}1.5-2.5^{\mathrm{b}} \\
1.89^{\mathrm{e}}\end{array}$ & \\
\hline Our study & & $1.19(0.76-1.86)^{f}$ & $1.41(0.92-2.19)^{f}$ & $1.07(0.69-1.69)^{f}$ \\
\hline $\begin{array}{l}\text { Proportion of asymptomatic infectious }(\theta, \%) \\
\text { Our study }\end{array}$ & $30 \%-50 \%^{\mathrm{g}}$ & $1 \%-82 \%$ & $1 \%-47 \%$ & $1 \%-40 \%$ \\
\hline $\begin{array}{l}\text { a } \text { Adopted from Flahault et al. }{ }^{37} \\
\text { b Adopted from Massad et al. } \\
\text { c }{ }^{31} \\
\text { d } \text { Adopted from Chowell et al. }{ }^{38} \\
\text { e Adopted from Mills et al. }{ }^{34} \\
\text { f } \text { Median }(95 \% \mathrm{Cl}) \text {. } \\
\text { g } \text { Adopted from Fraser et al. }{ }^{10}\end{array}$ & & & & \\
\hline
\end{tabular}

appearance of type B virus in Taiwan has also been discussed recently. ${ }^{6,26}$

The phenomena associated with these three (sub)type viruses are also similar to that of other countries. In Thailand, the positive rates of influenza $A$ and $B$ viruses in 2004 were $85.52 \%$ and $14.47 \%$, respectively (461 influenza A positive, 78 influenza B positive, out of a total of 539 infected specimens), and $65.77 \%$ and $34.22 \%$, respectively in the 2005 (492 influenza A positive, 256 type B positive, out of a total of 748 infected specimens). ${ }^{27}$ Most of the influenza-positive isolates in Taiwan were influenza A, which is consistent with the WHO reports on worldwide influenza activity. ${ }^{28}$

Carrat et al. ${ }^{3}$ reviewed a number of volunteer challenge studies, including experimental influenza infections, and discussed the dynamics of viral shedding, symptoms, and the relationship between viral shedding and illness in infected volunteers. Based on the findings of Carrat et al., ${ }^{3}$ the maximum quantum generation rate $\left(q_{\max }\right)$ for $\mathrm{A}$ $(\mathrm{H} 3 \mathrm{~N} 2)$ virus was estimated to be $9.22 \mathrm{TCID} \mathrm{h} \mathrm{h}^{-1}$ at droplet diameter of $10 \mu \mathrm{m}$ and day 3 post infection. The estimates of $q$ were proportional to the virus shedding patterns in respiratory fluids. This implied that influenza A virus was much more virulent than influenza B. Webster et al. ${ }^{29}$ also indicated that influenza $B$ virus normally exists at a lower prevalence and causes a milder disease severity than that of influenza A viruses, especially when compared to the $A(H 3 N 2)$ virus.

Dilution ventilation with fresh air in the Wells-Riley mathematical equation plays a crucial role in influenza infection. Natural or mechanical ventilations can both contribute to air change per hour $(\mathrm{ACH})$. In the hospital setting, many spaces generally utilize mechanical ventilation. Our results demonstrated a negative correlation with virus-specific infection risk $(P)$ and $\mathrm{ACH}$ rates.

There are several limitations to be noted in this study. Firstly, the Wells-Riley airborne infection model assumes conditions to be in steady state and infection constitutes a one-hit process. Secondly, the study also did not take into account the fact that the proximity of susceptible individuals to an infectious source is likely to influence their infection risk. Lastly, the proposed Wells-Riley mathematical equation also did not factor in the deposition or settling of droplet particles from the air. ${ }^{30}$

In this study, the virus-specific $R_{0}$ values were estimated to be 1.19 (95\% Cl 0.76-1.86), 1.41 (0.92-2.19), and 1.07 (0.69-1.69) for A $(\mathrm{H} 1 \mathrm{~N} 1), A(\mathrm{H} 3 \mathrm{~N} 2)$ and type $B$ viruses, respectively. Recently reported virus-specific estimates of $R_{0}$ and $\theta$ are listed in Table 4. Massad et al. ${ }^{31}$ analyzed the 1918 A (H1N1) pandemic outbreak in the city of São Paulo, indicating that the estimated $R_{0}$ value of 2.68 is comparable to estimates carried out for other influenza strains, such as estimates of 1.5 to 2.5 for the A (H3N2). Rvachev and Longini ${ }^{32}$ estimated an $R_{0}$ of 1.89 for the first wave of pandemic A (H3N2) which commenced in July 1968 in Hong Kong. Our findings in the present study regarding virus-specific $R_{0}$ estimates seem to be consistent with past research. However, at the time of writing, no relevant existed which related to influenza B virus. There is also insufficient data in the literature concerning the natural history of various strains of influenza to allow for accurate $\theta$ estimates. Constructing the $R_{0}-\theta$ relationship allows rapid mathematical prediction and comparisons between different vaccine efficacies to be drawn.

In conclusion, by integrating the experimental viral shedding characteristics, quantum generation rate, and Wells-Riley mathematical model, we were able to develop a quantitative framework describing infection risk and basic reproductive numbers of $A(\mathrm{H} 1 \mathrm{~N} 1), A(\mathrm{H} 3 \mathrm{~N} 2)$, and $B$ viruses. In the present investigation, the application of a $R_{0}-\theta$ critical control line was also able to simulate the controllable level, with vaccine efficacy values derived from match rate figures. Virus-specific infection risks were estimated by linking viral concentrations in human fluids with quantum generation rates. From this we were able to conclude that $A(H 3 N 2)$ virus exhibits a higher transmissibility and uncontrollable potential than $A(\mathrm{H} 1 \mathrm{~N} 1)$ and $B$ viruses.

\section{References}

1. Viboud C, Bjornstad ON, Smith DL, Simonsen L, Miller MA, Grenfell BT. Synchrony, waves, and spatial hierarchies in the spread of influenza. Science 2006;312:447-51. 
2. Hayden FG, Fritz RS, Lobo MC, Alvord WG, Strober W, Straus SE. Local and systemic cytokine response during experimental human influenza A virus infection. J Clin Invest 1998; 101:643-9.

3. Carrat F, Vergu E, Fergusion NM, Lemaitre $M$, Cauchemez $S$, Leach $\mathrm{S}$, et al. Time lines of infection and disease in human influenza: a review of volunteer challenge studies. Am J Epidemiol 2008;167:775-85.

4. Rambaut A, Pybus OG, Nelson MI, Viboud C, Taubenberger JK, Holmes EC. The genomic and epidemiological dynamics of human influenza A virus. Nature 2008;453:615-9.

5. Russell CA, Jones TC, Barr IG, Cox NJ, Garten RJ, Gregory V, et al. The global circulation of seasonal influenza A (H3N2) viruses. Science 2008;320:340-6.

6. Chen GW, Shih SR, Hsiao MR, Chang SC, Lin SH, Sun CF, et al. Multiple genotypes of influenza B viruses cocirculated in Taiwan in 2004 and 2005. J Clin Microbiol 2007;45:1515-22.

7. Hsieh YC, Chen HY, Yen JJ, Liu DP, Chang LY, Lu CY, et al. Influenza in Taiwan: seasonality and vaccine strain match. $\mathrm{J} \mathrm{Mi-}$ crobiol Immunol Infect 2005;38:238-43.

8. Anderson RM, May RM. Infectious diseases of humans: dynamics and control. Oxford: Oxford University Press; 1991.

9. Ferguson NM, Keeling MJ, Edmunds WJ, Gani R, Grenfell BT, Anderson RM, et al. Planning for smallpox outbreaks. Nature 2003;425:681-5.

10. Fraser C, Riley S, Anderson RM, Ferguson NM. Factors that make an infectious disease outbreak controllable. Proc Natl Acad Sci U S A 2004;101:6146-51.

11. King CC, Kao CL, Liu DP, Cheng MC, Yen HL, Lee MS, et al. Seven integrated influenza surveillance systems in Taiwan. Int Congr Ser 2001;1219:107-18.

12. Chang $\mathrm{CW}$, Wu KB, Huang TM, Chen $\mathrm{CH}$. Influenza activity in Taiwan: 2005/2006 season. Epidemiol Bull 2007;23: 489-504.

13. Lin JH, Chiu SC, Lee CH, Su YJ, Tsai HC, Peng YT. Genetic and antigenic analysis of epidemic influenza viruses isolated during 2006-2007 season in Taiwan. J Med Virol 2008;80:316-22.

14. Lin TY, Huang YC, Ning HC, Tsao KC. Surveillance of respiratory viral infections among pediatric outpatients in northern Taiwan. J Clin Virol 2004;30:81-5.

15. Lee JT, Chang LY, Wang LC, Kao CL, Shao PL, Lu CY, et al. Epidemiology of respiratory syncytial virus infection in northern Taiwan, 2001-2005-seasonality, clinical characteristics, and disease burden. J Microbiol Immunol Infect 2007;40: 293-301.

16. Nicas M, Nazaroff WW, Hubbard A. Toward understanding the risk of secondary airborne infection: emission of respiratory pathogens. J Occup Environ Hyg 2005;2:143-54.

17. Li Y, Leung GM, Tang JW, Yang X, Chao CYH, Lin JZ, et al. Role of ventilation in airborne transmission of infectious agents in the built environment - a multidisciplinary systematic review. Indoor Air 2007;17:2-18.

18. Duguid JP. The size and distribution of air-carriage of respiratory droplets and droplet-nuclei. J Hyg 1946;4:471-80.

19. Loudon RG, Roberts RM. Relation between the airborne diameters of respiratory droplets and the diameter of the stains left after recovery. Nature 1967;213:95-6.
20. Papineni RS, Rosenthal FS. The size distribution of droplets in the exhaled breath of healthy human subjects. J Aerosol Med 1997; 10:105-16.

21. Chen SC, Liao CM. Modeling control measure efforts to reduce the impact of pandemic influenza among schoolchildren. Epidemiol Infect 2008;136:1035-45.

22. Liao CM, Chen SC, Chang CF. Modeling respiratory infection control measure effects. Epidemiol Infect 2008;136:299-308.

23. Riley RL, Nardell EA. Clearing the air. The theory and application of ultraviolet air disinfection. Am Rev Respir Dis 1989;139: 1286-94.

24. Rudnick SN, Milton DK. Risk of indoor airborne infection transmission estimated from carbon dioxide concentration. Indoor Air 2003;13:237-45.

25. Chen R, Holmes EC. The evolutionary dynamics if human influenza B virus. J Mol Evol 2008;66:655-63.

26. Jian JW, Lai CT, Kuo CY, Kuo SHS, Hsu LC, Chen PJ, et al. Genetic analysis and evaluation of the reassortment of influenza $B$ viruses isolated in Taiwan during the 2004-2005 and 2006-2007 epidemics. Virus Res 2008;131:243-9.

27. Waicharoen $S$, Thawatsupha $P$, Chittaganpitch $M$, Maneewong P, Thanadachakul T, Sawanpanyalert P. Influenza viruses circulating in Thailand in 2004 and 2005. Jpn J Infect Dis 2008;61:321-3.

28. World Health Organization. Recommended composition of influenza virus vaccines for use in 2004-2005 influenza season. Wkly Epidemiol Rec 2004;79:85-92.

29. Webster RG, Bean WJ, Gorman OT, Chambers TM, Kawaoka Y. Evolution and ecology of influenza A viruses. Microbiol Rev 1992;56:152-79.

30. Escombe AR, Oeser CC, Gilman RH, Navincopa M, Ticona E, Pan W, et al. Natural ventilation for the prevention of airborne contagion. PLoS Med 2007;4:309-17.

31. Massad E, Burattini MN, Coutinho FA, Lopez LF. The 1918 influenza A epidemic in the city of Sao Paulo, Brazil. Med Hypotheses 2007;68:442-5.

32. Ravchev LA, Longini IM. A mathematical model for the global spread of influenza. Math Biosci 1985;75:3-23.

33. Thomas JC, Weber DJ. Epidemiologic methods for the study of infectious diseases. Oxford University Press; 2001.

34. Mills CE, Robins JM, Lipsitch M. Transmissibility of 1918 pandemic influenza. Nature 2004;432:904-6.

35. Anderson RM. The population dynamics of infectious diseases: theory and applications. London, New York: Chapman and Hall; 1982.

36. International Commission on Radiological Protection. ICRP Publication. Human respiratory tract model for radiological protection, a report of task group of the International Commission on Radiological Protection, vol. 66. New York: Elsevier; 1994.

37. Flahault A, Letrait S, Blin P, Hazou S, Menares J, Valleron J. Modelling the 1985 influenza epidemic in France. Stat Med 1988;7:1147-55.

38. Chowell G, Nishiura H, Bettencount LM. Comparative estimation of the reproduction number for pandemic influenza from daily case notification data. $J R$ Soc Interface 2007;4: 155-66. 